\title{
Research on Dynamic Coupling Measurement between Patent Portfolio and Target Enterprise
}

\author{
Wang Yue ${ }^{1, a}$, Wang Xin $^{2, b}$ \\ ${ }^{1}$ School of Business, University of Jinan, Ji'nan, Shandong Province, China \\ ${ }^{2}$ School of Business, University of Jinan, Ji'nan, Shandong Province, China \\ ayuewang@vip.163.com, b2642532569@qq.com
}

\begin{abstract}
Keywords: patent portfolio; target enterprise; dynamic coupling; interduality theory
Abstract. The focus of the patent portfolio design lies in how to use the relevant patent portfolio tool to convert knowledge of the company or the patent to the activities of commercial value. It is important particularly to realize the target company with the matching degree of patent portfolio value. The paper analyzed the characteristics of the Interduality of coupling system between the patent portfolio and the target enterprise. It established the model of coupling dynamic development between patent portfolio and target enterprise. An empirical study has been researched on Lenovo Group. It can effectively improve the performance of the whole system by the coordinated development between the Behavioral subsystem and the State subsystem. It will help to improve the performance of enterprises to balance the relationship between the construction of patent portfolio and the investment of resources.
\end{abstract}

\section{Introduction}

Patent is considered to be an indicator of the company's ability to innovate, and the patent itself also contains a wealth of information, it is an important intellectual asset of enterprises. Patent represents the company's R\&D result, the advantages and disadvantages of the patent will affect the value of the company, therefore, whether it is financial indicators (sales or sales growth rate) or market indicators (Tobin Q value or the value of the stock market), all these are proved by scholars that the number and the quality of patents have a positive impact on its value. In Chinese enterprises, the number of patent applications has exceeded the United States, Japan and other developed countries. However, Chinese enterprises from the patent benefits are far less than Europe, America, Japan and other developed countries. The reason is that patent quality is uneven so that enterprises cannot make profits from it. In other words, in most of the existing patents, only a small number of patents are of great value, the value of most other patents is not high ${ }^{[1]}$ (Schankerman\&Pakes, 1986), this is the contradiction of the patent. In order to explain the causes of patent contradictions, Wager (2005) proposed the concept of patent portfolio, this theory is based on the assumption that adding a new patent in a carefully constructed patent portfolio, the expected marginal revenue will be greater than that achieved when the marginal cost of the patent, so as to achieve the maximum overall efficiency ${ }^{[2]}$. Thus it can be seen, the enterprise can reach its maximum value through designing patent portfolio.

\section{Literature References}

The coupling between the patent portfolio and the target enterprise is also called collaborative development in most of the literature. At present, the researches of coupling degree measurement are mainly classified into the following 3 types. First, many foreign scholars' researches are mainly from these aspects, the matching of functions ${ }^{[3]}$ (Ensign,2001)、Collaborative mechanism ${ }^{[4]}$ (Koberg,2003), and so on. These studies are mainly through qualitative methods proposed on measuring the degree of collaboration, these methods are subjective measures and they are susceptible to be influenced by measuring person's personal understanding. Second, many scholars of our country have established synergy index system to measure it. Li Xianfeng ${ }^{[5]}(2005)$ designed four levels of enterprise and business partners to measure the degree of synergy in the study of collaborative 
business applications. Xu Xueguo and Qiu Yixiang ${ }^{[6]}$ (2005) use the synergy theory to analyse the organizational system synergy and build collaborative degree index evaluation system. Third, many scholars use various methods to establish a coordination degree model to measure the use of various methods. Such as Zeng Zhenxiang ${ }^{[7]}$ using membership function in fuzzy mathematics, constructs the coordination degree model to evaluate the system coordinated development. Meng Qingsong and Han Wenxiu $^{[8]}$ (2000) put forward a practical calculation of the overall composite system coordination model in the analysis of collaborative feature basis of coordination complex system

The two image is mainly embodied in the obvious nature of the coupling state in the development process in the whole system of patent portfolio and target enterprise coupling system, namely enterprises have measurable performance; and in the process of development, it still exists the nature of action, namely through the integration of resources (transformation) in order to achieve a certain state. Therefore, the development and evolution of the whole patent portfolio and the target enterprise coupling system have two different roles which are both state and behavior. The "state" is a static description of the system, and the "behavior" is a dynamic system to reach a state of reflection. Therefore, the evaluation of patent portfolio and target enterprise development can be measured by the trail of mutual influence, mutual transformation trajectory measure between the "state" system and "behavior" system. Harmony degree of system or system between elements in the evolution of each other is called collaborative degree. From the perspective of system theory, patent portfolio and target enterprise coupled system require technical resources and transformation ability have a common progress to have good performance, therefore, the state system and behavior system are complex system of mutual influence and mutual restriction. Patent portfolio and target enterprise coupling development system is an open system, state subsystem and behavior subsystem continuous energy with the outside world, the exchange of information at the same time, the functions, duties and other aspects are of great difference, far from equilibrium state. The interaction behavior between subsystems and subsystem is nonlinear, the fluctuation of some subsystem such as patent portfolio development or the size of resources, eventually led to the whole system from disorder to order. According to the above analysis, the formation must have four conditions according to dissipative structure, the two image system has the condition of applying the complex system coordination model.

\section{Measurement Model of Coupling Development of Patent Portfolio and Target Enterprise}

The Measurement Model of the Coupling Development Level of the Patent Portfolio and the

Target Enterprise. Patent portfolio and target enterprise coupling development is a complex system, patent portfolio and target of enterprise development refers to the two coupling system as state subsystem and subsystem behavior coordinated degree. Based on synergetics theory, the order parameters can be divided into fast relaxation variables and slow relaxation variables, slow relaxation variables determine the system evolution process. The system from disorder to order is the key to the coordinating role of the slow relaxation of variables, which determines the characteristics and evolution of the system. Therefore, after determining the system development of patent portfolio and target enterprise system as two coupling, through a study of two order parameters like system can determine the patent portfolio the coupling and target enterprise development path, and it can effectively measure the patent portfolio and target enterprise coupling development status.

According to Meng Qingsong, Han Wenxiu proposed the coordination degree model of the composite system, combined with the characteristics of the patent portfolio and the target enterprise coupling development system, this paper establishes the model of patent portfolio and target enterprise coupling development. The assumption that the state subsystem and the behavior subsystem of the patent portfolio and the target enterprise coupling development system are $s_{j j} j \in(1,2]$, The order parameter variable in the development process is $\theta_{j}=\left(\theta_{j 1}, \theta_{j 2}, \theta_{j n}\right)$, among $n \geq 1, \beta_{j 1} \leq g_{j 1} \leq a_{j 2}, \in[1, n]$. It is assumed that the greater the value of $\varphi_{j y}, \varphi_{j,}, \varphi_{j n}$, the higher the degree of order, the smaller the value of the system, the lower the degree of the system, it is assumed that the larger the value of $\theta_{j i+1, \ldots} \theta_{j n}$, 
the lower the degree of the system, the smaller the value, the higher the degree of the system. The order degree of order parameter component $\theta_{j i}$ of the state subsystem and the behavior subsystem is: $u_{j}\left(\theta_{j i}\right)=\left\{\begin{array}{c}\left(\theta_{j i}-\beta_{j i} / \alpha_{j i}-\beta_{j i}\right) i \in[1, n] \\ \left(\alpha_{j i}-\theta_{j i} / \alpha_{j i}-\beta_{j i}\right) i \in[l+1, n]\end{array}\right.$

(1)

Among them, $\alpha_{j i}$ and $\beta_{j i}$ are the upper and lower limits of the first $i$ index of the system. By the formula (1), $v_{j}\left(\theta_{j i}\right) \in[0,1]$, the greater the value, the greater the effect of $\varepsilon_{j}$ on the system order, the greater the effect of the system.

In general, index variable subsystem coordination degree of "contribution" is achieved by the integrated method. Integrated method is determined by the structure of the system in detail, this article is use of the geometric mean method to achieve.

$u_{j}\left(s_{j}\right)=\sqrt[n]{\prod_{i}^{n} u_{j}\left(\theta_{j i}\right)}$ or $u_{j}\left(s_{j}\right)=\sqrt[n]{\prod_{i=1}^{n} \lambda_{j} u_{j}\left(\theta_{j i}\right)} \lambda_{i} \geq 0, \sum_{i=1}^{n} \lambda_{j}=1$

$s_{j}$ represents the first $j$ subsystem, $w_{j}\left(s_{j}\right)$ indicates the subsystem coordination degree, $u_{j}\left(s_{j}\right) \in[0,1]$, the $u_{j}\left(s_{j}\right)$ is high, indicating that the subsystem coordination degree is high, greater contribution to the whole system and vice versa.

For a given initial time t0, state of each subsystem of the system coordination degree for $u_{1}^{0}\left(s_{1}\right)$, behavioral subsystem of system coordination degree for $u_{2}^{9}\left(a_{2}\right)$, for the whole system in the evolution process of the time $\mathrm{t} 1$ for, if this state subsystem coordination degree $u_{1}^{1}\left(s_{1}\right)$, behavioral subsystem coordination degree for the $u_{2}^{1}\left(s_{2}\right)$ and $u_{1}^{1}\left(s_{1}\right)-u_{1}^{0}\left(s_{1}\right) \geq 0, u_{2}^{1}\left(s_{2}\right)-u_{2}^{8}\left(s_{2}\right) \geq 0$, or the two formula also is less than zero, coupling degree of system can expressed as:

$c=\sqrt{\left|u_{1}^{1}\left(s_{1}\right)-u_{1}^{0}\left(s_{1}\right)\right|} \times \sqrt{\left|u_{2}^{1}\left(s_{2}\right)-u_{2}^{0}\left(s_{2}\right)\right|}$

From the above formula, it can be concluded that:

First, $c \in[0,1]$, the greater the value of $c$, the higher the overall coupling degree of the patent portfolio and the target enterprise coupling development system, the lower the contrary.

Second, two subsystems in the formula influence each other, if a subsystem coordination degree increases greatly, and another subsystem coordination degree improves smaller or falling, the whole system will be in poor coordination state or in a state of disharmony. There are only two subsystems synchronous growth or lower. The whole system is in coordination state. In addition, it is dynamic analysis that in subsystem coordination degree change in the grasp of the coordination state of the overall patent portfolio and target enterprise coupling development system.

Order Parameter Determination. Characterization of the states of each subsystem is enterprise performance. Therefore, according to the Ministry of Finance issued enterprise performance evaluation index system, the research achievements of scholars both at home and abroad in recent years and the purpose of this research and comprehensively considering China's electronic information manufacturing industry enterprise's actual situation, this paper selects three dimensions which can reflect the profitability, overseas market expansion and development ability to construct enterprise performance evaluation index system, and select three indicators the net assets income rate, the growth rate of main business income, overseas market earnings growth rate as the order parameter of the state system as shown in Table 1 shows.

Table 1 State subsystem order parameter

\begin{tabular}{|c|c|c|}
\hline Code & Index name & Calculating formula \\
\hline $\mathrm{X} 1$ & Return on equity & $\begin{array}{l}\text { Current term net profit / Average net assets during } \\
\text { the period }\end{array}$ \\
\hline $\mathrm{X} 2$ & Overseas market growth rate & $\begin{array}{c}\text { Overseas business income growth / Overseas } \\
\text { business income }\end{array}$ \\
\hline $\mathrm{X} 3$ & $\begin{array}{l}\text { Increase rate of main business } \\
\text { revenue }\end{array}$ & $\begin{array}{c}\text { Main business revenue growth / Main business } \\
\text { income last year }\end{array}$ \\
\hline
\end{tabular}

The behavior system includes two aspects, patent portfolio evolution system and enterprise resource transformation subsystem, and the evolution and transformation of patent resources combination are to make enterprises can achieve the goal effectively and to maximize the resource value of the 
principle, through a series of organizational behavior or a series of measures or behavior means to achieve the optimal allocation of resources and the state resources. The improvement and development of the patent portfolio is the key of the process of integration, so patent portfolio development is one of the key. This paper selects the overall growth rate of enterprise patent, overseas patent application patent portfolio as evolution subsystem of order parameters. The resource integration process reflects the enterprise operation efficiency and production efficiency improvement and specialized division of labor and cooperation. All these are based on financial resources, human resources and production equipment. Therefore, resource transformation capability is choosed and determined from human resources input, financial resources input and production equipment resources input and other angles. In view of this, this paper choose 3 indicators, R \& D funding, cost ratio, fixed asset growth rate, as behavioral subsystem sequence parameters. As shown in Table 2 and Table 3.

Table 2 Behavior subsystem (patent portfolio evolution subsystem) order parameter

\begin{tabular}{|c|c|c|}
\hline Code & Index name & Calculating formula \\
\hline Y1 & $\begin{array}{l}\text { Growth rate of patent } \\
\text { technology }\end{array}$ & $\begin{array}{c}\text { Number of increases in the number of patent applications } \\
\text { for this period / Number of patent applications at the } \\
\text { beginning of the period }\end{array}$ \\
\hline Y2 & $\begin{array}{l}\text { Number of overseas patent } \\
\text { applications }\end{array}$ & $\begin{array}{l}\text { Annual number of patent applications in the United } \\
\text { States, Japan and Europe }\end{array}$ \\
\hline Code & Index name & Calculating formula \\
\hline Z1 & $\begin{array}{l}\text { Increasing rate of fixed } \\
\text { assets }\end{array}$ & $\begin{array}{l}\text { The original value of fixed assets for the period / net } \\
\text { value of fixed assets at the beginning of the period }\end{array}$ \\
\hline $\mathrm{Z2}$ & R\&D Expenses & Investment in $\mathrm{R} \& \mathrm{D}$ process \\
\hline $\mathrm{Z3}$ & Expense ratio & Selling expenses / Management expenses \\
\hline
\end{tabular}

\section{An Empirical Analysis on the Coupling Development between the Patent Portfolio and the Target Enterprise}

Patent Portfolio and Target Enterprise Coupling Development System Two Image System Index Weight Determination. Before calculating the coordination degree of the two image system, first of all, the weight of the index variable of the two image system should be determined. Weight is the key link of the coupling degree measurement, it also have a direct impact on the final results of the evaluation. To determine the weight, this paper uses the factor analysis method. The calculation steps are as follows:

With $\mathrm{n}$ evaluation samples $\left\{p_{1}, p_{2}, \ldots p_{n}\right)$, each sample has $\mathrm{m}$ observation index $\left(x_{1}, x_{2}, \ldots, x_{n}\right\}$, so that it constitutes a $\mathrm{n} \times \mathrm{m}$ matrix $\mathrm{X}$, the elements are $x_{i j}$ :

In order to eliminate the influence of dimension, the data is standardized:

$z_{i j}=\frac{x_{i j}-\min (x)}{\max (x j-\min (x)}, i, j=1,2, \ldots, n i \neq j$ (Effect index)

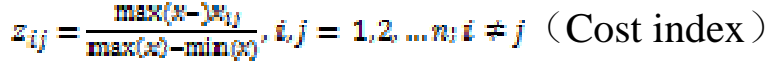

Formula: $\max (\mathrm{x}), \min (\mathrm{x})$, respectively the maximum and minimum elements in the matrix $\mathrm{X}$ after dimensionality reduction processing, $\mathrm{m}$ indicators can be represented by a linear combination of common factor $F_{1}, F_{2}, \ldots, F_{n}$, that is $Z=A F+E$, common factor matrix is $F=F_{1}, F_{2}, \ldots=F_{n}$.

After calculation, $F_{i}=\beta_{1}, \beta_{2}, \ldots, \beta_{n} \times z_{i} j=1,2, \ldots, m$, then, the weight of each index is:

$\omega_{i}=\frac{\sum_{j=1}^{m} \beta_{j i}}{\sum_{i=2}^{m} \Sigma_{j}^{m} \beta_{j i}}$

Input the original data of the patent portfolio and the target enterprise coupling development system SPSS18.0, after factor analysis, according to the principle of cumulative variance contribution rate 
reached $85 \%$, to get the factor score matrix analysis and then substituted into the formula (3), available:

$$
\begin{aligned}
& \omega_{1}=0.726, \omega_{2}=0.274, w_{2}=0.23, w_{4}=0.03 \\
& \omega_{5}=0.74, \omega_{6}=0.225, \omega_{7}=0.295, \omega_{2}=0.48
\end{aligned}
$$

State Subsystem and Behavior Subsystem Coordination Degree Determination. This paper takes Chinese electronic information manufacturing industry listing Corporation Lenovo for example, discusses it from the beginning of 2005 after the acquisition of IBM has been coupled to patent portfolio and target enterprise development system between 2015 .The data is mainly from the sample enterprise 2005 to 2015 annual report, and then in accordance with the requirements of the data to collate and calculate.Put the original data into the formula system development of patent portfolio and target enterprise coupling (1), obtained the order of the state system and behavior system order parameter of each component, obtained in Table 4.

Table4 Ordered degree of order parameters of the state subsystem and the behavior subsystem

\begin{tabular}{cccccccccc}
\hline Year & $\begin{array}{c}\text { Patent } \\
\text { growth } \\
\text { rate }\end{array}$ & $\begin{array}{c}\text { Overseas } \\
\text { patent } \\
\text { application }\end{array}$ & $\begin{array}{c}\text { R \& D } \\
\text { investment }\end{array}$ & $\begin{array}{c}\text { Expense } \\
\text { ratio }\end{array}$ & $\begin{array}{c}\text { Fixed asset } \\
\text { investment } \\
\text { growth rate }\end{array}$ & $\begin{array}{c}\text { Fixed } \\
\text { assets } \\
\text { invest } \\
\text { ment }\end{array}$ & $\begin{array}{c}\text { Increase rate } \\
\text { of main } \\
\text { business } \\
\text { revenue }\end{array}$ & $\begin{array}{c}\text { Overseas } \\
\text { market } \\
\text { growth } \\
\text { rate }\end{array}$ & $\begin{array}{c}\text { Return } \\
\text { on } \\
\text { equity }\end{array}$ \\
\hline 2005 & 0.53 & 0.00 & 0.00 & 0.00 & 0.07 & 0.02 & 0.29 & 0.94 & 0.53 \\
2006 & 0.15 & 0.04 & 0.51 & 0.57 & 1.00 & 1.00 & 0.36 & 0.00 & 0.15 \\
2007 & 0.39 & 0.27 & 0.51 & 0.68 & 0.52 & 0.04 & 0.47 & 0.42 & 0.39 \\
2008 & 0.57 & 0.66 & 0.57 & 0.79 & 0.25 & 0.07 & 0.00 & 1.00 & 0.57 \\
2009 & 0.00 & 0.22 & 0.56 & 0.94 & 0.06 & 0.00 & 0.30 & 0.53 & 0.00 \\
2010 & 0.38 & 0.23 & 0.55 & 0.94 & 0.00 & 0.06 & 0.76 & 0.20 & 0.38 \\
2011 & 0.50 & 0.33 & 0.68 & 0.96 & 0.04 & 0.11 & 1.00 & 0.45 & 0.50 \\
2012 & 1.00 & 0.47 & 0.82 & 0.60 & 0.84 & 0.13 & 0.27 & 0.61 & 1.00 \\
2013 & 0.32 & 1.00 & 0.94 & 0.91 & 0.34 & 0.06 & 0.85 & 0.76 & 0.32 \\
2014 & 0.14 & 0.84 & 1.00 & 1.00 & 0.47 & 0.06 & 0.75 & 0.89 & 0.14 \\
\hline
\end{tabular}

Put the data in Table 4 into the formula $u_{j}\left(s_{j}\right)=\sqrt[*]{\prod_{i=1}^{2} \lambda_{j} u_{j}\left(\theta_{j i}\right)}$, the coordination degree of the behavior subsystem and the state subsystem can be obtained, obtained in Table 6.

Table5 Coordination degree of each subsystem

\begin{tabular}{cccc}
\hline Year & $\begin{array}{c}\text { Coordination degree of patent } \\
\text { portfolio evolution subsystem }\end{array}$ & $\begin{array}{c}\text { Resource conversion } \\
\text { subsystem coordination } \\
\text { degree }\end{array}$ & $\begin{array}{c}\text { Enterprise performance } \\
\text { subsystem coordination } \\
\text { degree }\end{array}$ \\
\hline 2005 & 0.0000 & 0.0000 & 0.0531 \\
2006 & 0.0340 & 0.1145 & 0.0000 \\
2007 & 0.1456 & 0.0978 & 0.0627 \\
2008 & 0.2745 & 0.0838 & 0.0000 \\
2009 & 0.0000 & 0.0528 & 0.0000 \\
2010 & 0.1322 & 0.0000 & 0.0646 \\
2011 & 0.1832 & 0.0516 & 0.1151 \\
2012 & 0.3046 & 0.1283 & 0.0871 \\
2013 & 0.2540 & 0.1135 & 0.1103 \\
2014 & 0.1518 & 0.1335 & 0.1105 \\
\hline
\end{tabular}

The Coupling Degree Calculation of the Patent Portfolio and the Target Enterprise Coupling Development System. The behavior and state will be calculated by the three sub system coordination degree of substitution system integrated and coordinated development level measurement formula, we can get the enterprise patent portfolio and enterprise development coupling system coupling degree. As shown in Table 7 below. 
Table 6 System coupling degree

\begin{tabular}{cccccccccc} 
Year & 2006 & 2007 & 2008 & 2009 & 2010 & 2011 & 2012 & 2013 & 2014 \\
\hline $\begin{array}{c}\text { Coupling } \\
\text { degree }\end{array}$ & 0.5777 & 0.3885 & 0.1212 & 0.1244 & 0.0788 & 0.0676 & 0.2231 & 0.1067 & 0.0794 \\
\hline
\end{tabular}

According to the above calculation results, draw the coupling development trend of Lenovo Group patent portfolio and enterprise coupling development trend chart, as shown in Fig.1.

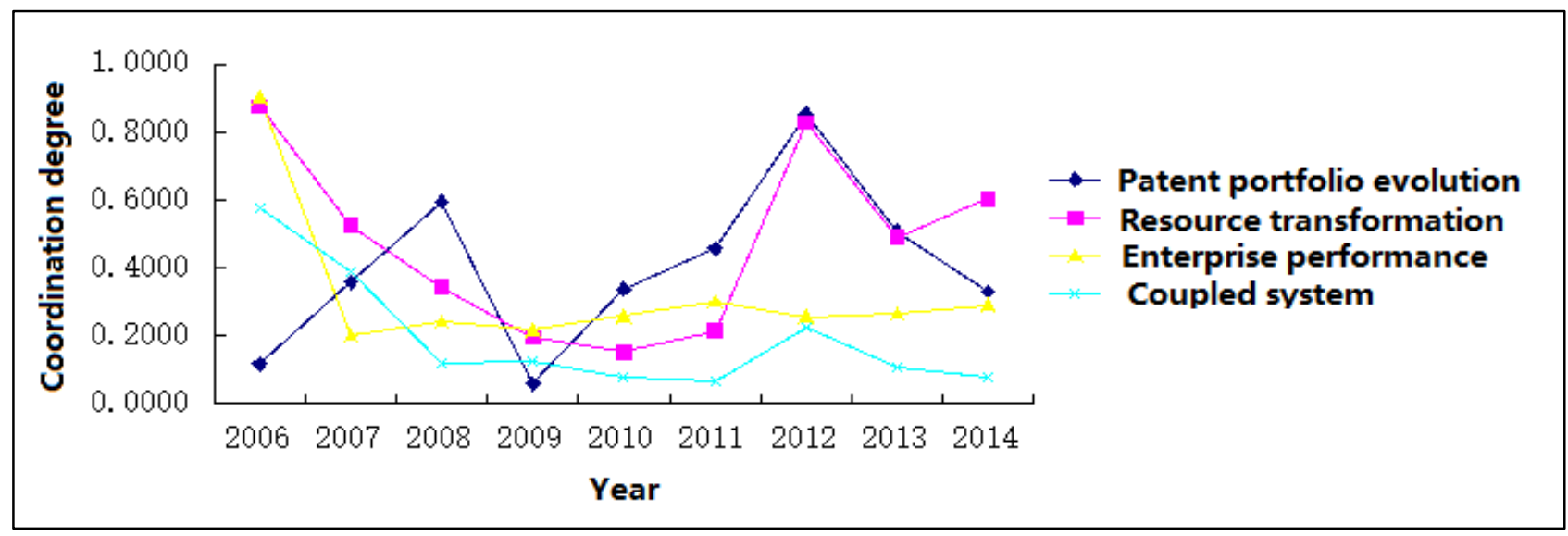

Fig.1 Lenovo group patent portfolio and enterprise coupling development trend chart

Fig.1 shows that during the period from 2006 to 2014, Lenovo patent portfolio evolution subsystem, resource conversion subsystem and enterprise performance subsystem are reduced after the first growth trend. During the period from 2004 to 2010, each subsystem coordination degree decreased year by year, it shows that in the period of this time, enterprise development is not enough coordination, especially resource transformation subsystem has been in a state of decline, and it is not consistent with the overall development and operation of the enterprise. After 2010, the coordinated development of behavior subsystem and the state subsystem have improved, that the order degree of the whole enterprise is relatively high and the development is coordinated; overall, the development trend of patent portfolio system explains, Lenovo Group in evolution patent portfolio process focuses on the continuity and development and the degree of order continuously improves. But resource transformation subsystem coordinated development situation is not ideal, it has been in a state of decline, although in 2012-2013 years it has improved, but the overall level is not high, the development is not enough coordination.

Order of the enterprise performance system is relatively stable, each order parameter has a basic coordinated development. Only the coordinated development of behavior subsystem and state subsystem effectively, the performance of the system can be promoted. From the trend of Lenovo patent portfolio and enterprise development system coupling group, the coupling degree is not ideal, but after 2010, it shows a trend of increasing year by year, gradually to the coordinated development. However, the development of system of patent portfolio and enterprise coupling degree also has been below 0.15, it is running low and it shows that the enterprise should study the patent portfolio and the enterprise resource integration in an effective way, and make full use of the advantages of patent portfolio to produce value and reflect the enterprise performance.

As shown in Fig.1, 2010 has become the turning point of the coordinated development of the patent portfolio and the enterprise coupling development system, the degree of coupling development of the state subsystem is significantly increased, and the coordination degree of the two subsystems is increased simultaneously. The main reasons include three points, one is in 2004, after the Lenovo Group determining the way of international expansion, in 2005, it experienced the acquisition of IBM's personal computer business enterprises, and finally Enterprises embarked on the road of rapid 
development. In 2006, the Lenovo Group increases investment on research and development, but in the operation of patent portfolio is not mature, the patent administration department has just established, that the patent portfolio operations and development situation are not ideal. The two is the allocation of resources in the performance to there is a gradual process. It also makes the 2006-2009 annual state system and behavior system order degree are low. The three, although Lenovo is not broken increased resources transformation efforts, but from the resource conversion subsystem development view, and the coordinated development level is not high, personnel management, equipment investment research and development investment don't translate into a competitive power, there is also a discordant.

\section{Conclusions and Recommendations}

Overall, Lenovo Group's patent service and enterprise development coupled are not ideal, the coupling degree has been in a state of decline, although in 2011 it has improved, but overall it still has been in low running state. According to the research conclusion, put forward the following suggestions.

First, to further improve the patent portfolio construction. In recent years, through the purchase of patents, mergers and acquisitions and other means, Lenovo Group has been won the large number of patents, but it is not perfect. In particular, some of the important high value and high technology content of the patent are difficult to obtain through the purchase. Therefore, Lenovo Group should be on the purchase of the foundation, increase own research and development efforts, and in a technical field with full patent portfolio to deal with enterprise development needs.

Second, to further strengthen the resource transformation investment and to fully exploit the patent portfolio value. In recent years, Lenovo has been increased investment, in fixed assets, cost management, R \& D investment and other aspects, it shows the rapid growth of the situation. However, the rapid growth of investment did not return performance, coordination degree of resource transformation system has been in the low and declining trend. This shows that although the resource input is in growth but did not play a role. In the future, enterprises should focus on analysis of the existing problems in the operation of patent portfolio, the increase in mergers and acquisitions whether the patent value and so on. Especially in recent years, Lenovo obtains patent portfolio through the purchase of a large number of mergers and acquisitions and other means, if the resources cannot be sent volatile its value, this kind of merger and acquisition will affect the sustainability of enterprise development.

Third, balance the patent portfolio construction and transformation of resource input relations and improve enterprise performance. At present, Lenovo Group as a whole in an inconsistent state, so its performance improvement is relatively slow. The main reason is that through the purchase and other means to obtain the patent portfolio, the enterprise is difficult to quickly upgrade the transformation ability of the products. Thus, we should increase R \& D investment and enhance the ability of independent innovation, it will be more conducive to the transformation of technology to the product, it is the only way of the future development of enterprises.

\section{References}

[1] Schankerman, M., \& Pakes, A. (1986). Estimates of the value of patent rights in European countries during the post-1950 period. The economic journal, 1052-1076

[2] Wagner, R. P., \& Parchomovsky, G. (2005). Patent portfolios. University of Pennsylvania Law Review, 154(1)

[3] Prescott C. Ensign, The Concept of Fit in Organizational Research. International Journal of Organization Theory and Behavior, 2001(4):287-306 
[4] Christine S. Koberg, Dawn R. Detienne, Kurt A. Heppard, An empirical test of environmental, organizational, and process factors affecting incremental and radical Innovation. Journal of High Technology Management Research, 2003,14(1):21-45

[5] Li Xianfeng, Bai Qinghua, Deng Song. Research on the obstacles and Countermeasures of collaborative commerce application. Modern management science, 2005, (12):12-13 (in Chinese)

[6] Xu Xueguo, Qiu Yixiang, Peng Zhenglong. Design and application of collaborative evaluation model of organizational learning. Systems engineering, 2005, 23(6):6-11 (in Chinese)

[7] Zeng Zhenxiang, Gu Peiliang. Systematic analysis and evaluation of sustainable development. Beijing: Science Press, 2000 (in Chinese)

[8] Meng Qingsong, Han Wenxiu. Research on coordination degree model of composite system. Journal of Tianjin University (NATURAL SCIENCE EDITION), 2000(4):444-446 (in Chinese) 